\title{
Prevalence and Risk Factors of Uncontrolled Asthma among Adults in a South Indian Tertiary Care Hospital
}

\author{
Suresh Sagadevan ${ }^{1}$, Aruna Shanmuganathan ${ }^{2}$, Meenakshi Narasimhan ${ }^{3}$, Nisha Ganga ${ }^{4}$
}

${ }^{1}$ Department of Respiratory Medicine, Chettinad Hospital and Research Institute, Kelambakkam, Tamilnadu, India. ${ }^{2}$ Department of Respiratory Medicine, Chettinad Hospital and Research Institute, Kelambakkam, Tamilnadu, India.

${ }^{3}$ Department of Respiratory Medicine, Chettinad Hospital and Research Institute, Kelambakkam, Tamilnadu, India.

${ }^{4}$ Department of Respiratory Medicine, Chettinad Hospital and Research Institute, Kelambakkam, Tamilnadu, India.

\section{ABSTRACT}

\section{BACKGROUND}

Globally, around 300 million people suffer from Bronchial asthma, the prevalence of which is predicted to increase in the ensuing decades. Prevalence rates range from 4$18 \%$ worldwide with around $2.05-3.5 \%$ reported in India. In spite of availability of updated guidelines from GINA \& recent therapeutic advances, asthma control is still not being achieved in a significant proportion of patients. Uncontrolled asthma is associated with greater exacerbations, poorer quality of life \& higher mortality which lead to considerable socioeconomic burden and emotional stress for patients and their families. The complex interaction of several variables including patient and disease related factors play a role in poor asthma control. Limited Indian studies especially in the South are available to assess the prevalence and risk factors of uncontrolled asthma. Hence, the present study was undertaken to enable recognition of modifiable risk factors in uncontrolled asthma which could serve as a platform to plan suitable interventions to achieve optimum asthma control. We wanted to estimate the prevalence of uncontrolled asthma among adult asthma patients and assess the risk factors associated with uncontrolled asthma.

\section{METHODS}

This is a cross sectional observational study. Adults with a diagnosis of asthma (Global Initiative of Asthma- GINA guidelines) for a duration of at least 1 year were administered validated \& piloted questionnaire by telephonic interview or physical visit to assess demographic data, risk factors \& level of control of asthma. Data was analysed using SPSS 20.0. Quantitative data expressed in Mean \& SD. Unpaired T test $\&$ Chi square test to assess association of continuous \& dichotomous variables.

\section{RESULTS}

A total of 110 asthmatics (M:F=59:51) with a mean age $35.25 \pm 12.34$ years and mean BMI $25.75 \pm 3.80$ were included in the study. Well controlled, partly controlled and uncontrolled asthma were $11.8 \%, 39.1 \%$ \& $49.1 \%$ respectively. Risk factors associated with uncontrolled asthma were elderly, obesity, smoking, pollution \& GERD.

\section{CONCLUSIONS}

Asthma control in the majority was uncontrolled. Increasing age, obesity, smoking \& GERD were risk factors significantly associated with poor asthma control.

\section{KEY WORDS}

Uncontrolled Asthma, Adults, Risk Factors
Corresponding Author: Aruna Shanmuganathan, Villa 97, Aqua Lily, Mahindra World City, Chengelpet-603002, Tamilnadu, India. E-mail: draruna.shanmuganathan@gmail.com

DOI: $10.14260 /$ jemds/2019/698

Financial or Other Competing Interests: None.

How to Cite This Article:

Sagadevan $S$, Shanmuganathan A, Narasimhan $M$, et al. Prevalence and risk factors of uncontrolled asthma among adults in a South Indian tertiary care hospital. J. Evolution Med. Dent. Sci. 2019;8(43):3220-3224 $10.14260 /$ jemds $/ 2019 / 698$

Submission 25-08-2019,

Peer Review 08-10-2019,

Acceptance 15-10-2019,

Published 28-10-2019. 


\section{BACKGROUND}

Asthma is a widely prevalent chronic inflammatory disease with more than 300 million people affected globally and it is predicted that another 100 million new cases would be added by $2025.1,2$ In India, prevalence of adult asthma is reported between $2.05 \& 3.5 \%$. Despite availability of effective medications \& updated guidelines for its management, a significant proportion of patients continue to remain poorly controlled with prevalence rates ranging from $30-70 \%$ across various countries.3,4,5,6,7 Uncontrolled asthma is associated with a higher rate of exacerbations, poorer quality of life and greater decline of lung function with time. This leads to a substantial socioeconomic burden ${ }^{4}$ and emotional stress for patients, families and the society at large. To overcome the disparities associated with classification of asthma based on severity alone, the Global Initiative of Asthma (GINA) proposed the modified asthma classification based on the level of control achieved. 8 This included frequency of diurnal and nocturnal symptoms, use of rescue medications and activity limitation. The complex interaction of several factors including patient and disease related issues play a role in suboptimum level of asthma control. Studies show that factors like poor adherence to maintenance therapy, incorrect inhaler technique, suboptimal medication prescriptions and various co morbidities including obesity, smoking and reflux disease were associated with poor asthma control.7,9 and 10

Very few Indian studies especially in the south are available on the prevalence and risk factors for uncontrolled asthma in adults ${ }^{9}$ Hence the current study was undertaken to enable us to identify the burden of uncontrolled asthma and region specific risk factors, if any in order to plan appropriate strategies with the ultimate goal of achieving the maximum level of asthma control.

\section{METHODS}

The study design was cross sectional observational conducted in the Department of Respiratory medicine, Chettinad Hospital \& Research Institute, Chennai, Tamilnadu which is a tertiary care health care facility. Institutional Ethics committee clearance was obtained for the study. The study period was between January 2016 and June 2017.

Inclusion criteria were all adults $>18$ years of age of both genders with a diagnosis of asthma according to GINA guidelines for a duration of at least one year. Other causes of obstructive airway disease like bronchiectasis, post TB Obstructive airway disease were excluded. Informed consent was obtained from all the participants.

The subjects were then administered a structured, validated and piloted questionnaire regarding demographic information like age, gender, occupation, educational status, BMI and presence or exposure to specific risk factors like smoking, pollution, reflux disease and comorbidities like diabetes, thyroid disorders and exacerbations. The level of control of their asthma was assessed by the GINA endorsed asthma control questionnaire whose scores classified subjects as well, partly and uncontrolled asthma. Questionnaire administration was done either by telephonic interview or on physical visit by trained personnel.

\section{Statistical Analysis}

Data was analyzed by SPSS 20.0 software. Quantitative data was expressed in mean and standard deviation. Unpaired $\mathrm{T}$ test and Chi square test were used to assess association of continuous and dichotomous variables with uncontrolled asthma respectively.

\section{RESULTS}

A total of 110 subjects completed the questionnaire satisfactorily. The male: female ratio was 59:51 and mean age of subjects was $35.25 \pm 12.34$ years with majority of them (59.1\%) belonging to the 26-45-year age group. The mean body mass index (BMI) was $25.75 \pm 3.80$ and $62.8 \%$ were overweight and obese.
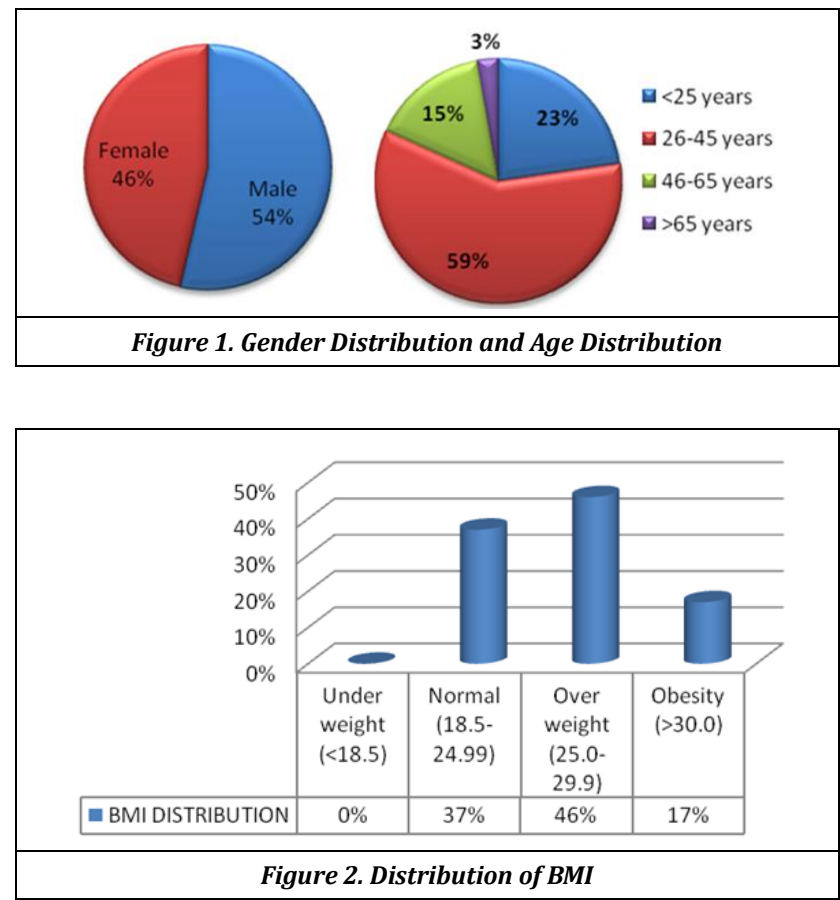

The level of asthma control as assessed by the GINA questionnaire showed that out of the total of 110 subjects, the number of well, partly and uncontrolled asthma subjects were 13 (11.8\%), 43 (39.1\%) and $54(49.1 \%)$ respectively. Hence, $49.1 \%$ of subjects had uncontrolled asthma. Poorly controlled asthma (Partly and uncontrolled) constituted $88.2 \%$.

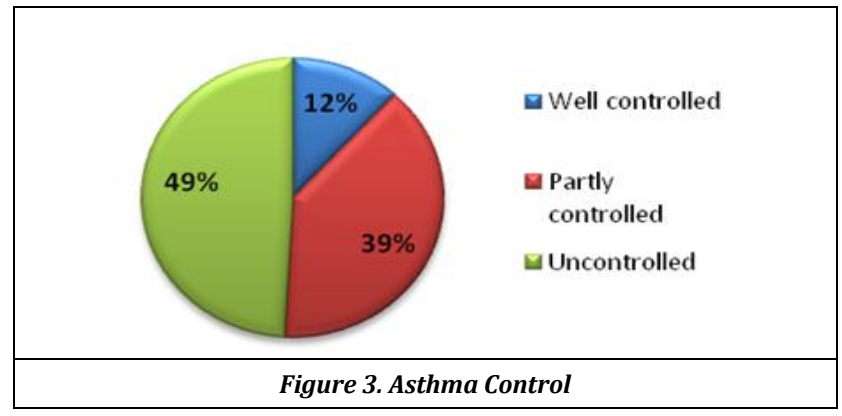




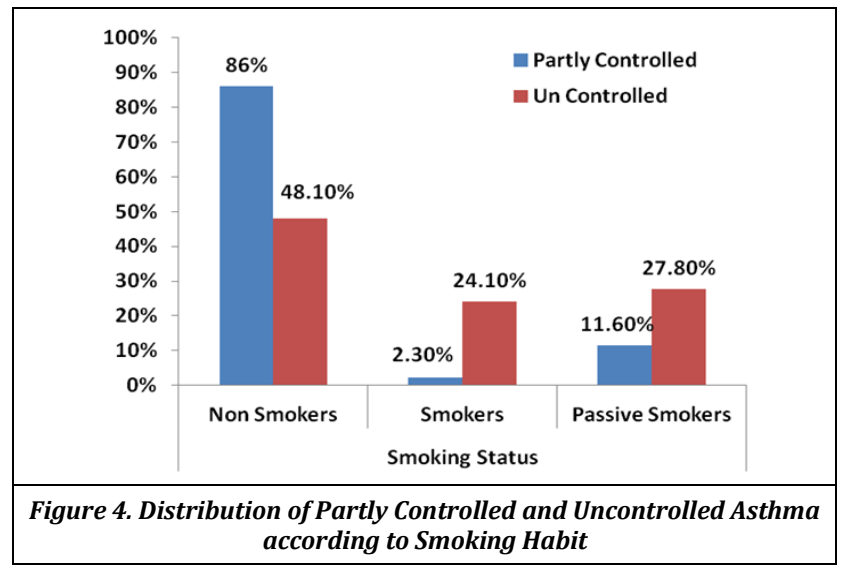

\begin{tabular}{|c|c|c|c|c|}
\hline \multirow[b]{2}{*}{ Variables } & \multicolumn{3}{|c|}{ Types of Poorly Controlled Asthma } & \multirow{2}{*}{$\begin{array}{c}\text { Chi Square } \\
\text { Value \& } \\
\text { p-Value }\end{array}$} \\
\hline & $\begin{array}{r}\text { Total } \\
\mathrm{N}=97\end{array}$ & $\begin{array}{c}\text { Partly Controlled } \\
n(\%) 43(44.3)\end{array}$ & $\begin{array}{c}\text { Uncontrolled } \\
\text { n (\%) } 54 \text { (55.7) }\end{array}$ & \\
\hline \multicolumn{5}{|c|}{ Gender } \\
\hline Male & $56(57.7)$ & $22(51.2)$ & $34(63.0)$ & 1.366 \\
\hline Female & $41(42.3)$ & $21(48.8)$ & $20(37.0)$ & 0.243 \\
\hline \multicolumn{2}{|l|}{ Age } & $28.79 \pm 9.28$ & $39.80 \pm 12.43$ & $\begin{array}{l}-4.832 \\
0.0001^{* *}\end{array}$ \\
\hline \multicolumn{5}{|c|}{ Age Groups } \\
\hline$\leq 50$ years & & $42(97.7)$ & $43(79.6)$ & 7.190 \\
\hline$>50$ years & & $1(2.3)$ & $11(20.4)$ & $0.0001^{* *}$ \\
\hline \multicolumn{5}{|c|}{ Educational Qualifications } \\
\hline School & $45(46.4)$ & $11(25.6)$ & $34(63.0)$ & 13.450 \\
\hline Graduate & $52(53.6)$ & $32(74.4)$ & $20(37.0)$ & $0.011^{*}$ \\
\hline \multicolumn{5}{|c|}{ Occupational Status } \\
\hline Working & $56(57.7)$ & $23(53.5)$ & $33(61.1)$ & 0.570 \\
\hline Non-Working & $41(42.3)$ & $20(46.5)$ & $21(38.9)$ & $0.450^{5}$ \\
\hline \multicolumn{2}{|l|}{ BMI } & $24.12 \pm 2.66$ & $27.35 \pm 4.07$ & $\begin{array}{l}-4.506 \\
0.0001 * *\end{array}$ \\
\hline \multicolumn{5}{|c|}{ Body Mass Index Classifications } \\
\hline $\begin{array}{l}\text { Normal Weight } \\
(18.5-24.9)\end{array}$ & $35(36.1)$ & $22(51.2)$ & $13(24.1)$ & \multirow{3}{*}{$\begin{array}{l}19.407 \\
0.0001^{* *}\end{array}$} \\
\hline $\begin{array}{l}\text { Over Weight } \\
(25.0-29.9)\end{array}$ & $44(45.4)$ & $21(48.8)$ & $23(42.6)$ & \\
\hline $\begin{array}{c}\text { Obese } \\
(\geq 30.00)\end{array}$ & $18(18.6)$ & $0(0)$ & $18(33.3)$ & \\
\hline \multicolumn{5}{|c|}{ Type of Smoking Habit } \\
\hline Non Smokers & $63(64.9)$ & $37(86.0)$ & $26(48.1)$ & \multirow{3}{*}{$\begin{array}{l}16.167 \\
0.0001^{* *}\end{array}$} \\
\hline Smokers & $14(14.4)$ & $1(2.3)$ & $13(24.1)$ & \\
\hline $\begin{array}{l}\text { Passive } \\
\text { Smokers }\end{array}$ & $20(20.6)$ & $5(11.6)$ & $15(27.8)$ & \\
\hline \multicolumn{2}{|c|}{$\begin{array}{c}\text { Duration of Asthma } \\
\text { in years }\end{array}$} & $7.63 \pm 5.43$ & $13.83 \pm 8.02$ & $\begin{array}{c}-4.344 \\
0.0001^{* *}\end{array}$ \\
\hline \multicolumn{5}{|c|}{ Hospitalization Classification $(>2 /$ Year $)$} \\
\hline Absent & $62(63.9)$ & $38(88.4)$ & $24(44.4)$ & 20.029 \\
\hline Present & $35(36.1)$ & $5(11.6)$ & $30(55.6)$ & $0.0001^{* *}$ \\
\hline \multicolumn{5}{|c|}{ Smoking Status } \\
\hline Non Smokers & $63(64.9 \%)$ & $37(86.0 \%)$ & $26(48.1 \%)$ & \multirow{3}{*}{$\begin{array}{l}16.167 \\
0.0001^{\wedge * *}\end{array}$} \\
\hline Smokers & $14(14.4 \%)$ & $1(2.3 \%)$ & $13(24.1 \%)$ & \\
\hline $\begin{array}{c}\text { Passive } \\
\text { Smokers }\end{array}$ & $20(20.6 \%)$ & $5(11.6 \%)$ & $15(27.8 \%)$ & \\
\hline \multicolumn{5}{|c|}{ Pollution } \\
\hline Absent & $25(25.8)$ & $16(37.2)$ & $9(16.7)$ & 5.280 \\
\hline Present & $45(83.3)$ & \begin{tabular}{|l|l|}
$27(62.8)$ \\
\end{tabular} & $45(83.3)$ & $0.022^{*}$ \\
\hline \multicolumn{5}{|c|}{ Diabetes Mellitus } \\
\hline Absent & $74(76.3)$ & $43(100.0)$ & $31(57.4)$ & 24.007 \\
\hline Present & $23(23.7)$ & $0(0)$ & $23(42.6)$ & $0.0001^{* *}$ \\
\hline \multicolumn{5}{|c|}{ Hypertension $(\mathrm{n}=64)$} \\
\hline Absent & $85(87.6)$ & $43(100.0)$ & $42(77.8)$ & 10.905 \\
\hline Present & $12(12.4)$ & $0(0)$ & $12(22.2)$ & $0.001^{* *}$ \\
\hline \multicolumn{5}{|c|}{ GERD } \\
\hline Absent & $45(46.4)$ & $31(72.1)$ & $14(* 25.9)$ & 20.516 \\
\hline Present & $52(53.6)$ & $12(27.9)$ & $40(74.1)$ & $0.0001^{* * \wedge}$ \\
\hline \multicolumn{5}{|c|}{ OSA } \\
\hline Absent & $88(90.7)$ & $43(100)$ & $45(83.3)$ & 7.900 \\
\hline Present & $9(9.3)$ & $0(0)$ & $9(16.7)$ & $0.004^{* * \wedge}$ \\
\hline $\begin{array}{r}\text { Table 1. Ass } \\
\text { amon }\end{array}$ & $\begin{array}{l}\text { ociation of } \\
\text { Partly an }\end{array}$ & $\begin{array}{l}\text { f Baseline Variable } \\
\text { nd Uncontrolled As }\end{array}$ & $\begin{array}{l}\text { e with Type of As } \\
\text { sthma Patients ( }\end{array}$ & $\begin{array}{l}\text { Ima Control } \\
=97)\end{array}$ \\
\hline Note: ${ }^{\wedge}$ Fishel & $\begin{array}{l}\text { SExact }-\mathrm{Ch} \\
(\mathrm{p}<0.05) ; * *\end{array}$ & $\begin{array}{l}\text { i Square Test Value; } \$ \mathrm{~N} \\
\text { Very Highly Statistically }\end{array}$ & $\begin{array}{l}\text { Jot Significant }(p>0.05 \\
\text { y Significant }(p<0.01)\end{array}$ & ; *Significant \\
\hline $\begin{array}{l}\text { Chi - Square ar } \\
\text { significant asso } \\
\text { increasing age, } \\
\text { GERD and OSA } \\
\text { educational qu } \\
\text { and was statist }\end{array}$ & $\begin{array}{l}\text { higher BI } \\
\text { were sta } \\
\text { alification }\end{array}$ & $\begin{array}{l}\text { tyalysis were used to } \\
\text { type of control. Uncontr } \\
\text { duration of Asthma, smo } \\
\text { ically significant with } p- \\
\text { d pollution were also as }\end{array}$ & $\begin{array}{l}\text { dentify the factors tha a } \\
\text { rolled Asthma was ass } \\
\text { oking, diabetes mellit } \\
\text { - value }<0.01 \text { as shon } \\
\text { ssociated with uncont } \\
5 \text { as shown Table. }\end{array}$ & $\begin{array}{l}\text { showed } \\
\text { ciated with } \\
\text {; hypertension; } \\
\text { in table. Lower } \\
\text { olled asthma }\end{array}$ \\
\hline
\end{tabular}

\section{DISCUSSION}

Though updated guidelines and effective medications are available to achieve optimum asthma control, in practice and real life only a minority of patients are well controlled with a good quality of life and normal daily activities. Uncontrolled asthma still remains a challenge contributing to significant socioeconomic burden and emotional stress for patients and their families. ${ }^{2,4,10}$ In view of the discordance between severity of asthma/lung function and level of control, GINA in 2006 proposed a revised classification of asthma based on level of control. According to the new system a patient is well controlled if the diurnal symptoms and use of reliever medications were less than twice a week and there were no nocturnal awakenings or activity limitation in the last one month. Data from many western studies reveal that the prevalence rates for uncontrolled asthma ranged between 30 and $60 \% .7,8,9,10$ However, studies from developing nations especially India is limited, and estimates vary from 70$95 \% .{ }^{11,12,3}$ Hence, the current study was undertaken to assess the burden of uncontrolled asthma and its association with risk factors in a tertiary care hospital in South India.

Our study included 110 patients with a male to female ratio of 59:51. Majority of them (59.1\%) belonged to the 26-45 yr., age group. According to their BMI distribution, $62.8 \%$ were overweight and obese.

The level of control as assessed by the validated GINA questionnaire showed that out of 110 subjects, $49.1 \%$ and $39.1 \%$ had uncontrolled and partly controlled asthma contributing to a total of $88.2 \%$ of poor asthma control. Only $11.8 \%$ were well controlled. Western studies show the prevalence of uncontrolled asthma ranging from $34.3 \%$ in a Latin American country to $53.2 \%$ in a study in Spain..$^{8,9}$ An Italian study however, showed a reasonably proportion with good control(64.4\%)and $19.8 \%$ who were uncontrolled A study on the Asthma Insights and Reality in Asia Pacific region (ARIAP), found that in both adults and children, asthma control was way far from optimum. $51.4 \%$ and $44.3 \%$ reported daytime and nocturnal symptoms with $44.7 \%$ having limitations in daily activities.2,12 However, asthma control according to GINA was not evaluated. The Asthma Insights and Management study in the Asia Pacific region (AP-AIM) reports Indian data showing that though $91 \%$ of asthmatics perceived good control, none of them had optimum control by objective criteria. ${ }^{12}$ The International Asthma Patient Insight Research (INSPIRE) study which was a multinational study reported prevalence of $51 \%$ and $28 \%$ for uncontrolled and well controlled asthma. ${ }^{13}$ Compared to developed nations, studies in developing countries show a higher proportion of poorly controlled asthma as in a Chinese study ${ }^{14}$ showing more than $80 \%$ with poor control and Indian studies reporting $30-35 \%$ as well controlled.11,12,13 Hence our study shows a high percentage of subjects (88.2\%) with poorly controlled asthma.

The socio demographic factors in our study which were significantly associated with uncontrolled asthma were increasing age $>50$ years, higher BMI including overweight and obese subjects and lower educational status. Gender was not significantly correlated when partly controlled and uncontrolled asthma was compared in the present study. Some studies, $3,7,8,15$ have reported that women were more likely to have poorer asthma control while others have not found any gender association. ${ }^{5,12} \mathrm{~A}$ few European studies 3,12 and Indian 
studies ${ }^{11,12}$ showed that elderly were at increased risk of uncontrolled asthma. Our study also demonstrated the age $>50$ years was significantly associated with poorer control. Similar observations from other studies also implicate increasing age as a risk factor for uncontrolled asthma. 7,8,11

Lower educational status was a risk factor for poorly controlled asthma in our study. The study by Agrawal et al $^{3}$ which included subjects from the National Family Health Survey reported that uncontrolled asthma was associated with illiteracy as also the Asia pacific-Asthma Insights \& Management AP-AIM study though the association in the latter was not statistically significant.12 Other studies also report lower educational status with poor asthma control.6,14,15

Our study showed a significant correlation with increasing BMI and uncontrolled asthma. Overweight and obese subjects had worse control of their status. Various mechanisms have been postulated for obesity as a risk factor for development of asthma and insufficient control ranging from the low grade systemic inflammation associated with obesity to increased airway hyper reactivity and the role of leptin and adiponectin. ${ }^{16}$ Western studies also show that obese asthmatics had worse control.17,18 An Indian and Middle East and Chinese study also associate obesity and poor control. 3,6,14 On the contrary, studies by Clerisme-Beaty et al and Sastre et al did not show association between asthma control and obesity. ${ }^{19,20}$ Among the co morbidities OSA was found to be significantly associated with poor control in our study. The Asia Pacific and other studies also reported increasing BMI and OSA as risk factors for suboptimal control. 3,10,11,12

The other risk factor identified in our study which was significantly associated with uncontrolled asthma was smoking. Smoking is responsible for accelerated decline in lung function and is one of the major aetiologies in COPD. Asthmatic smokers represent a unique phenotype and these individuals have higher exacerbations, poorer asthma control and greater morbidity and mortality. Angelica Tiotiu et al and a few Indian studies report smoking association with worsening asthma control and also corticosteroid unresponsiveness. 3,5,21,22 The Asia Pacific study and a Swedish study by Stallberg et al also showed that smoking was associated with uncontrolled asthma similar to our study.7,12 Hence GINA recommends smoking cessation as an important tool in asthma management.

Gastroesophageal reflux disease (GERD) has been associated with asthma in many studies. ${ }^{23,24,25}$ The postulated mechanisms are that acid reflux leads to inflammatory changes in airways causing bronchospasm through vagal mediation and micro aspiration. Some studies have shown improvement of asthma symptoms with typical GERD symptoms following GERD treatment 23,24 our study showed that GERD was significantly associated with poor asthma control similar to another Indian study. However, a study by Brent et al,26 reported that treatment of asthmatics that have silent GERD with anti-reflux medications did not improve asthma control, though in asthmatic patients with frank symptoms of GERD, proton pump inhibitors treatment resulted in lesser asthma exacerbations. Hence, GERD is also an important risk factor affecting the optimal control of asthma. Among the co morbidities assessed as risk factors for uncontrolled asthma, Diabetes and hypertension were found to have a significant association with uncontrolled asthma in our study. Serafina-Agrusa et al have showed asthma severity to be linked to the control of diabetes. ${ }^{27}$ another study demonstrated that impaired glucose tolerance was associated with higher numbers of asthma exacerbations. ${ }^{28}$

Pollution was found to be significantly associated with uncontrolled asthma in our study. Both acute and chronic exposure to air pollution is found to be associated with greater number of asthma exacerbations, hospitalizations and reduced lung function. Similar observations were also seen in a few studies. ${ }^{29}$ Greater susceptibility to the effects of ambient air pollution was seen in children and changes in daily levels of pollution were associated with variable lung function and symptoms. ${ }^{29}$ Hence, air pollution plays an important role in asthma control.

Hence, to summarise, our study showed that almost half the subjects had uncontrolled asthma with around $88 \%$ being poorly controlled. This reflects that even with effective treatment options a significant number of asthmatics still remain far from optimum control. The important risk factors identified in our study which were significantly associated with uncontrolled asthma were increasing age, higher BMI \& OSA, lower educational status, smoking and pollution and comorbidities like GERD, diabetes and hypertension.

\section{CONCLUSIONS}

Uncontrolled asthma is still widely prevalent in India. The major risk factors associated with poor control were elderly, obesity, OSA, GERD, smoking and pollution. Hence, achievement of optimum asthma control needs to address several factors including sociodemographic and modifiable risk factors in addition to ensuring education regarding medication compliance and proper inhalational techniques.

\section{REFERENCES}

[1] Thompson PJ, Salvi S, Lin J, et al. Insights, attitudes and perceptions about asthma and its treatment: findings from a multinational survey of patients from 8 AsiaPacific countries and Hong Kong. Respirology 2013;18(6):957-67.

[2] Gold LS, Thompson P, Salvi S, et al. Level of asthma control and health care utilization in Asia-Pacific countries. Respiratory Medicine 2014;108(2):271-7.

[3] Agrawal S, Pearce N, Ebrahim S. Prevalence and risk factors for self-reported asthma in an adult Indian population: a cross-sectional survey. The International Journal of Tuberculosis and Lung Disease 2013;17(2):275-82.

[4] Koul PA, Dhar R. Economic burden of asthma in India. Lung India: official organ of ICS 2018;35(4):281-3.

[5] Jindal SK, Aggarwal AN, Gupta D, et al. Indian Study on Epidemiology of Asthma, Respiratory Symptoms and Chronic Bronchitis in adults (INSEARCH). Int J Tuberc Lung Dis 2012;16(9):1270-7.

[6] AL-Jahdali H, Wali S, Salem G, et al. Asthma control and predictive factors among adults in Saudi Arabia: results from the epidemiological study on the management of asthma in asthmatic middle-east adult population study. Ann Thorac Med 2019;14(2):148-54. 
[7] Kämpe M, Lisspers K, Stallberg B, et al. Determinants of uncontrolled asthma in a Swedish asthma population: cross-sectional observational study. European Clinical Respiratory Journal 2014;1:10.3402/ecrj.v1.24109.

[8] Del Carmen VM, Picado C, Herraez L, et al. Factors associated with severe uncontrolled asthma and the perception of control by physicians and patients. Arch Bronconeumol 2014;50(9):384-91.

[9] Marchioro J, Gazzotti MR, Nascimento OA, et al. Level of asthma control and its relationship with medication use in asthma patients in Brazil. Journal brasileiro de pneumologia: publicacao oficial da Sociedade Brasileira de Pneumologia e Tisilogia 2014;40(5):487-94.

[10] Fulvio B. Failure in asthma control: reasons and consequences. Article ID 549252, Scientifica 2013;2013: p. 15.

[11] Gosavi S, Nadig P, Haran A. Factors contributing towards poor asthma control in patients on regular medication. Journal of Clinical and Diagnostic Research: JCDR 2016;10(6):0C31-5.

[12] Salvi SS, Apte KK, Dhar R, et al. Asthma insights and management in India: lessons learnt from the Asia Pacific - Asthma Insights and Management (AP-AIM) Study. The Journal of the Association of Physicians of India 2015;63(9):36-43.

[13] Partridge MR, Van der Molen T, Myrseth SE, et al. Attitudes and actions of asthma patients on regular maintenance therapy: the INSPIRE study. BMC Pulmonary Medicine 2006;6:13.

[14] Yang D, Lin J, Zhou X, et al. Real world evaluation of asthma control risk factors and management: findings from China national asthma control surveys. Eur Res J 2017;50:PA3986.

[15] Ställberg B, Lisspers K, Hasselgren M, et al. Asthma control in primary care in Sweden: a comparison between 2001 and 2005. Primary Care Respiratory Journal 2009;18(4):279-86.

[16] Baffi CW, Winnica DE, Holguin F. Asthma and Obesity: mechanisms and clinical implications. Asthma Research and Practice 2015;1:1.

[17] Maalej S, Yaacoub Z, Fakhfakh R, et al. Association of obesity with asthma severity, control and quality of life. Tanaffos 2012;11(1):38-43.

[18] Novosad S, Khan S, Wolfe B, et al. Role of obesity in asthma control, the obesity-asthma phenotype. Journal of Allergy (Cairo) 2013;2013:538642.
[19] Clerisme-Beaty EM, Karam S, Rand C, et al. Does higher body mass index contribute to worse asthma control in an urban population? The Journal of Allergy and Clinical Immunology 2009;124(2):207-12.

[20] Sastre J, Olaguibel JM, Vina LA, et al. Increased body mass index does not lead to a worsening of asthma control in a large adult asthmatic population in Spain. Journal of Investigational Allergology and Clinical Immunology 2010;20(7):551-5.

[21] Tiotiu A, Wirth N, Martinet Y. Influence of tobacco smoking on asthma control. European Respiratory Journal 2016;48:PA3365.

[22] Boulet LP, FitzGerald JM, McIvor RA, et al. Influence of current or former smoking on asthma management and control. Can Respir J 2008;15(5):275-9.

[23] Parsons JP, Mastronarde JG. Gastroesophageal reflux disease and asthma. Curr Opin Pulm Med 2010;16(1):603.

[24] Sandur V, Murugesh M, Banait V, et al. Prevalence of gastro-esophageal reflux disease in patients with difficult to control asthma and effect of proton pump inhibitor therapy on asthma symptoms, reflux symptoms, pulmonary function and requirement for asthma medications. J Postgrad Med 2014;60(3):282-6.

[25] Harding SM, Richter JE, Guzzo MR, et al. Asthma and gastroesophageal reflux: acid suppressive therapy improves asthma outcome. Am J Med 1996;100(4):395405.

[26] Riscili BP, Parsons JP, Mastronarde JG. Treating silent reflux disease does not improve poorly controlled asthma. Cleveland Clinic Journal of Medicine 2010;77(3):155-60.

[27] Serafina-Agrusa L, Spatafora M, Scichilone N. Asthma and metabolic syndrome: current knowledge and future perspectives. World Journal of Clinical Cases 2015;3(3):285-92.

[28] Ghamin H. Impaired glucose tolerance test and exacerbation. J Diabetes Res 2015;202406.

[29] Jacquemin B, Kauffmann F, Pin I, et al. Air pollution and asthma control in the Epidemiological study on the Genetics and Environment of Asthma. Journal of Epidemiology and Community Health 2012;66(9):796802. 